\title{
Comet mission collapses as craft disappears
}

Tony Reichhardt, Washington

Comet research in the United States is facing an uncertain future after mission managers all but gave up hope of salvaging the CONTOUR (Comet Nucleus Tour) spacecraft. The craft went silent on 15

Out with a bang: NASA's comet-seeking craft CONTOUR may have met a premature end.

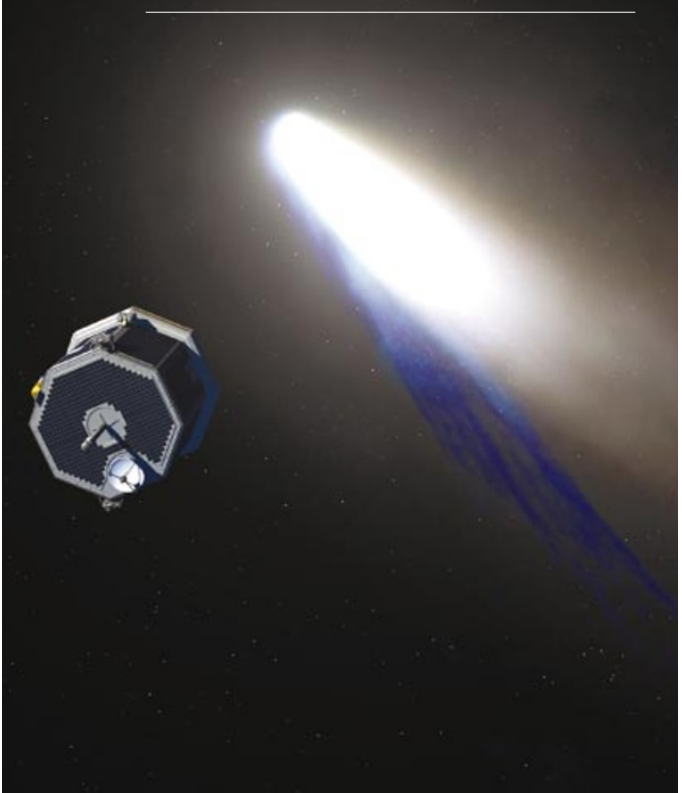

August as it fired an onboard rocket to leave Earth orbit.

The NASA-funded spacecraft was built and operated by the Johns Hopkins University Applied Physics Laboratory (APL) near Baltimore, Maryland. It was supposed to have visited two comets in four years, beginning with Comet Encke in 2003, to take close-up photographs of their icy nuclei (see Nature 417, 889; 2002). Now the \$159million mission seems to be a total loss.

For US comet investigators, CONTOUR's demise is the latest and most calamitous in a long line of setbacks. The United States was the only major spacefaring nation not to send a craft to Halley's Comet in 1986, and several NASA comet projects have been cancelled since, including the Comet Rendezvous Asteroid Flyby a decade ago, and a US lander for Europe's Rosetta mission, which is expected to rendezvous with a comet in 2011.

CONTOUR had operated flawlessly in the weeks after its 3 July launch, circling Earth as its orbit shifted gradually into the proper alignment to head towards Encke. This 'indirect launch mode' technique, pioneered on this mission, was designed partly to allow the use of a cheaper launch vehicle. Once the orbit was aligned, an onboard rocket motor fired to boost CONTOUR into interplanetary space.

Ground controllers had expected to establish radio contact with the spacecraft shortly after the engine fired, but they never received a signal. Then, one day after CONTOUR vanished, the Spacewatch asteroidtracking telescope in Arizona photographed two small objects streaking away from Earth at a distance of about 460,000 kilometres, in roughly the position CONTOUR would be if the rocket had fired. Mission managers took this as evidence that the spacecraft had broken into two pieces after the rocket fired, or that some part had come detached.

With no telemetry data or additional pictures, it will be difficult to determine what happened to CONTOUR. Although radio and optical telescopes continued searching the sky, APL managers were not optimistic about regaining contact as of early this week.

Mission director Robert Farquhar of APL was non-committal about whether his team might repropose the mission to NASA. CONTOUR was funded under the agency's Discovery programme for planetary exploration, and its price tag was only half the typical cost of such a mission. But other cometary spacecraft are being prepared for launch in the next few years, and it would take the CONTOUR team at least that long to ready a replacement.

For Farquhar, CONTOUR's loss was especially frustrating. "I wrote my first paper on getting to Encke's comet in 1972," he told the press last week. "I've been at this for 30 years, so I would like to have gotten some images."

\section{Nobel laureate's dream for brain research finds home}

\section{Alison Abbott, Rome}

An Italian competition to host a European Brain Research Institute (EBRI) has been won by a private hospital in Rome.

The institute is the brainchild of Nobel laureate Rita Levi-Montalcini, who personally organized the national competition without waiting for support or financial backing from the Italian government or any other institution.

The EBRI will be housed in a new building at Rome's Santa Lucia Hospital, which specializes in rehabilitating patients with neuromotor problems.

But as yet the new institute has no guaranteed funding to cover its running costs. Officials at Santa Lucia are relying on the hospital's growing status in Italian research, and on the reputation of Levi-Montalcini, to attract funds.

"We are confident that funding for some positions will emerge in next year's budget," says Luigi Amadio, director of the Santa Lucia Foundation, which owns the hospital. He also hopes to win support from the European Union.

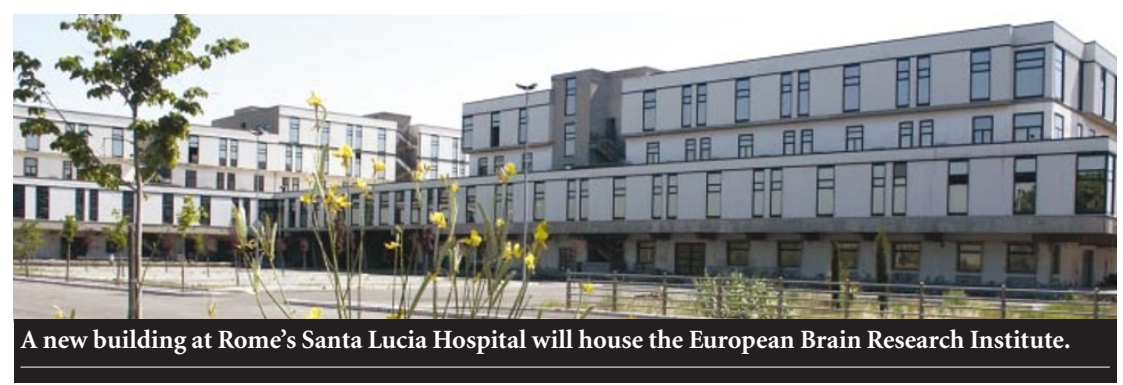

Levi-Montalcini, now 93, first mooted the concept of the EBRI last September, describing it as a truly European centre to attract foreign scientists into Italy, as well as offering Italian neuroscientists a chance to return home.

"I was surprised by the enthusiastic response from the scientific community," says Levi-Montalcini. Sites in Rome, Turin and Varese, near Milan, applied to host the centre.

The successful application was spearheaded by Amadio and neurologist Giorgio Bernardi of Rome's Tor Vegata University, who also works at the hospital. In recent years, Amadio and Bernardi have greatly expanded research at Santa Lucia, and in 1992 it was awarded a 'research hospital' status, which allows it to apply for additional funds from the health ministry. Since then its research income has risen from 250,000 euros (US\$245,000) to 9 million euros last year, and it now employs 125 researchers.

Levi-Montalcini is also establishing an international scientific committee for the EBRI to recruit scientists, who will be able to establish research groups in any neuroscience field. "I'd like to see a holistic approach at the EBRI, with lots of crossfertilization," she says. 